\section{Positions Available}

\section{FACULTY POSITION University of Dayton}

Electro-Optics Program at the University of Dayton, administered by its School of Engineering, is seeking applicants for a tenure-track faculty position at either assistant or associate professor level. The position is expected to be filled by January 1993. The successful candidate will teach graduate electro-optics lecture and laboratory courses, pursue vigorous research programs in optical materials, supervise/advise graduate students, and attract external funding. We seek an outstanding experimentalist with an earned PhD in optics, or material science/engineering, or related fields. Applications from women and minorities are especially welcome. Applicants should send a curriculum vitae, a statement of research interests, and three letters of recommendation to: Dr. Mohammad A. Karim, Center for ElectroOptics, University of Dayton, Dayton, Ohio 45469-0227 by July 31, 1992.

\section{ENDOWED CHAIR IN SOLID STATE ELECTRONICS Rensselaer Polytechnic Institute}

Rensselaer Polytechnic Institute is soliciting applications and nominations for a newly endowed Roberts' Chair in Solid State Electronics. The endowed Chair is a commitment from Rensselaer alumnus and co-founder of Fairchild Semiconductor, C. Sheldon Roberts, and his wife, Pat. The Chairholder should be internationally known and be capable of providing scientific and technological leadership in microelectronics. Research emphasis can include semiconductor and packaging materials and processing, solid state devices, electronic/ photonic systems, modeling and characterization.

The Chairholder must qualify as a professor in the Electrical, Computer and Systems Engineering (ECSE) Department and be a strong contributor to the interdisciplinary Center for Integrated Electronics (CIE) at Rensselaer. The ECSE Department has over 40 faculty members with major strengths in the areas of solid state/integrated electronics, automatic controls/robotics, communications and information processing, computer engineering and fusion plasmas. The $\mathrm{CIE}$ has a broad-based research focus in interconnections and interfaces, including silicon and compound semiconductor devices and interfaces, multilevel metallization and interlayer dielectrics, thin-film packaging and high-performance digital and analog design. Both the ECSE Department and the CIE are major components of a Rensselaer strategic focus in the area of manufacturing, materials and design. Applications, nominations and inquiries should be addressed to: Prof. Ronald J. Gutmann, Director of the CIE and Professor of ECSE, Rensselaer Polytechnic Institute, Troy, New York 12180-3590 or by electronic mail to rgutmann@unix.cie.rpi.edu.

Rensselaer is an affirmative action/equal opportunity employer.

\title{
A Posterminaries in Three Movements
}

A premise: The RED enterprise is sick. The symptoms presented by the patient must be examined, a diagnosis must be arrived at, and a treatment must be prescribed before the patient expires. In January, we tackled elucidation of symptoms and their interrelationships. In March, we charitably diagnosed the root cause as sensory deprivation. Now it's time to design a treatment and hazard a prognosis. We had warned not to expect a miracle cure. Reports on the patient's condition may be sent to the Bulletin as Letters to the Editor.

\section{Taking the Collective Cure An Edifice Complex}

Suppose the ventilation system of the building where you work is spreading malevolent microbes. You fall ill, consult your physician, take the miracle drug of the day, and you're cured. Right? Wrong! Prognosis: (1) you'll be re-infected, and (2) your work will be hurt directly or indirectly by the absence of similarly ill colleagues. Moral: the most successful episodic individual treatment will fail unless the entire complex takes the cure.
Our "building" is the R\&D edifice. The narrowly targeted episodic treatments have been such therapies as massive injections of pork and the rhetoric of breakthrough-sculpted hyperbole plastered on each incremental advance. Roy ${ }^{1}$ writes that it is "... a sign of the state of modern science that the advertising that now accompanies even minor (occasionally even trivial) 'discoveries' gets louder and shriller with time. It seems as though academic scientists believe that science must appear to advance only by 'breakthroughs, artificial if not real, to retain the allegiance of an increasingly skeptical public. ...Unfortunately, agencies and managers even a little distance removed from the field get all caught up in the 'excitement.' "

Recognizing the folly in our hype, Koshland ${ }^{2}$ confesses tongue-in-cheek to repeatedly protesting that science needs more funding and that the benefits of science far outweigh the deleterious side effects. He blames his need to harp on the issue on "the politicians, the bureaucrats, and others who do not instantly see the wisdom of [his] words." Koshland earlier postulated $^{3}$ that the more unlikely a project, the greater the need for a public relations expert. These treatments are worse than the disease. Prognosis: we will catch it again!

To recount additional misguided remedies accomplishes little. To reverse an epidemic we would need to prescribe some truly hackneyed cliches such as a paradigm shift or a sea change.

\section{Intrinsic Aversions}

Some doubt that rehabilitation in concert is feasible. Park ${ }^{4}$ points out that trying to get physicists to agree to anything can be compared to herding cats. I dare say most of us are "physicists" in this respect, particularly when it comes to being herded onto unfamiliar ground. ${ }^{5}$

Unfamiliar are the political and commercial grounds. To become entrained in the political process has run counter to our nature. Bromley ${ }^{6}$ realizes that scientists and engineers in the United States 
have tended to keep reasonably removed from the political process because Congress and the taxpayer have been remarkably generous to us since the war years. But Hobson' tells us that staying aloof from the process rests on fiction. He believes that a distinction between science and its uses may be convenient for academicians, but the distinction doesn't exist in the real world. If science is moral and political, then scientists must concern themselves with the moral and political consequences of their work, however broadly or narrowly they construe their work. (Hobson, of course, speaks of "moral" in a weapons-work context, but substituting other national or commercial needs leaves his point unaltered.)

\section{The Antisepsis of Honesty}

The ducts in our building have nurtured disease because they've been either full of hot air or left closed and stagnant. They need the antisepsis of cool, fresh air. This means our patterns must shift to a middle course beyond quiet desperation but far short of blatant overselling. We know "the nature of basic research is such that no one can predict where, when, or to whom the benefits will flow," as Bromley ${ }^{6}$ acknowledges, and "because of that, no single institution can justify the necessary investment." We must therefore sell the discovery process rather than the unpredictable product. After all, as Kleppner ${ }^{8}$ puts it, scientific discoveries invariably exceed the power of our imagination, not because we are shortsighted but because "nature is inexhaustible."

In March we posited that "sensory deprivation" is the root of our problemthat we have lost touch with the evolving external context of our work. The remedies, which are out of context and out of proportion to the magnitude of local trauma, go with this territory. Calls upon us to see the new reality and to refrain from such excursions are getting louder. Roy entreats, "Modesty and service to our patron society must become our style again."

So, we must re-establish the perceived value of what it is we do in the minds of those who pay us to do it, not just surrogates we deal with directly, but the original source of the funds (i.e., taxpayers and stockholders). Society must see not near-term, unfulfilled, empty promises, but the value of our efforts over time.

This is a difficult challenge not merely because of what we do and how we do it, but because of who we are. By both task and temperament, we are not those who should or can be "managed," even for our own good, without due acknowledgment of the creative process as fragile and as anathema to conventional rigid approaches. To learn how to better communicate our concerns and aspirations, we must first understand ourselves in the broader context of the society we speak to. That will determine whether we come across as delightfully unique or decidedly peculiar.

\section{Bitter Pills}

Medication for sensory deprivation is large doses of quality contact. Just as the crucial characteristics of a good $R \& D$ manager are distinctly nonscientific, so must be the characteristics of the quality contact needed to successfully bridge our troubled interfaces. Except for newborns (i.e., K-12ers), all of us must swallow the prescription below and suffer some side effects if we plan on continued breathing. Some will likely compare this to surgery without benefit of anesthesia.

\section{$R x$ (bis in die)}

1. Accept with equanimity:

- the nontechnical and nonrational components of the science policy decision process. Remember, Congress is distracted by far broader a mandate than just good science: e.g., local and national economic vitality, jobs, trade balances, national security, esprit de corps (in the vein of the Sputnik-ignited race for space), and re-election campaigns;

- the corporate imperative of profitability; and

- that supply and demand forces apply to our fields.

2. Never forget we are a tax on a tax: $R \& D$ is a small percentage discretionary investment in the future and the " $R$ " part is a smail percentage of that! Acting as though we belong at center stage wins few friends.

3. Communicate! Talk and listenindividually and collectively. Don't just explain who we are and what we want. Learn the customers' motives, both superficial and fundamental.

4. Change fields if indicated by a longterm projection of customer needs and desires.

5. Keep the faith-stick to doing science scientifically and don't be badgered into skipping intermediate steps. The results will come back to haunt us if control experiments are omitted, if reproducibility is not assured, if technically or economically infeasible products are predicted, and if archival publication is skipped in favor of the New York Times.

6. Influence society's directions and attitudes through tailored-to-the-listener advice for those who need it now and through education of their successors and our future customer base. This will necessitate setting foot outside our building and hobnobbing face to face with our neighbors.

Roy ${ }^{9}$ rightly complains that the degree of abstraction in technical educationaway from felt and experienced reality -is what has isolated the entire culture of science and technology from the lay people. He contends that to put science back into its proper place, education needs to be reconceptualized from the abstract to the concrete. This will ultimately rescue basic science, "which is quickly running out of things to study at a price the public is willing to pay."

\section{Prognosis}

We can make today's yet-to-bediscovered science and yet-to-be-invented technology real to a technically literate public who will, in turn, demand patience for the process from business and government. Alienation will transmute to conciliation and to support as our view of that support retreats from perpetual entitlement to down payment on our technological future.

If these pills are too big to swallow, we can surmise a treatment-independent prognosis-sooner or later, even if left untreated, the R\&D enterprise will survive and thrive. Humankind's innate curiosity and inventiveness guarantee that. Whether we reach that renaissance traveling a rational and comfortable itinerary or whether we need to be reborn from the rubble of our self-inflicted folly is the choice we face. Most likely we'll try to mold our own fortunes rather than chance a chaotic process in the hands of others, but our ailment, while not fatal, will still take its toll. High-risk groups will be lost at the margin and the margin will be uncomfortably wide.

\section{E.N. KAUFMANN}

\section{References}

1. R. Roy, Adv. Mater, 3 (1991) p. 448.

2. D.E. Koshland Jr., Science 255 (1992) p. 9.

3. D.E. Koshland Jr., Science 254 (1991) p. 917.

4. R. Park, What's New, American Physical Society, electronic bulletin board, November 1, 1991.

5 . Indeed, the issue of individual prerogatives versus communal duties extends well beyond the technical community and has even spawned a new journal, The Responsive Community: Rights and Responsibilities, edited by A. Etzioni (Center for Policy Research, Washington, DC).

6. D.A. Bromley, Interview, MRS Bulletin XVII (2) (1992) p. 22-25.

7. A. Hobson, Physics and Society, 20 (4) (newsletter of the APS Forum on Physics and Society, October 1991) p. 16.

8. D. Kleppner, Physics Today (December 1991) p. 9.

9. R. Roy, MRS Bulletin XVII (3) (1992) p. 5-9.

For a second opinion, see A. Kantrowitz, Physics Today (March 1992) p. 61. 